\title{
O PAPEL DO ANTEPARO NA MODELAGEM FÍSICA DE CINTURÕES COMPRESSIVOS - UM ESTUDO APLICADO A UM DUPLEX DO TIPO PILHA ANTIFORMAL
}

\author{
Caroline Janette Souza Gomes (*)
}

\begin{abstract}
In order to analyze the effect of a moving wall on experimental thrust systems, the progressive evolution of antiformal stacks was simulated in sandbox models. The rigid, acrylic moving wall was substituted by analogue material. Different boundary conditions demonstrated that in physical models the use of the habitual stiff wall obstructs the development of the real architecture of compressional tectonics.
\end{abstract}

\section{INTRODUÇ̃̃̃O}

A Tectônica Experimental constitui uma ferramenta poderosa para a Geologia Estrutural/Geotectônica e sua importância é hoje mundialmente reconhecida para corroborar modelos teóricos sobre a configuração estrutural de ambientes tectônicos. Grande número de autores se baseia nas simulações da modelagem física analógica para explicar e descrever mecanismos de deformação. Livros didáticos modernos de geologia estrutural e Tectônica, publicados na década de noventa, apresentam capítulos inteiros sobre processos deformacionais tratados quase exclusivamente sob a ótica da simulação por materiais analógicos (p. ex. Price \& Cosgrove 1990; Hancock 1994).

Modelagens físicas de estruturas compressivas têm sido descritas na literatura internacional enfocando principalmente mecanismos de dobramentos e de geração de sistemas de falhas, além de estudos de casos. Os experimentos são efetuados em caixas de madeira ou acrílico, em geral retangulares, de 50 a $100 \mathrm{~cm}$ de comprimento e 20 a $30 \mathrm{~cm}$ de largura, nas quais a parede frontal móvel, acoplada a um motor, gera a deformação.

No ano de 1992, Marshak \& Wilkerson publicaram os resultados de um estudo experimental sobre a influência da espessura de uma coluna de areia sobre a geração de falhas de cavalgamento. Pela primeira vez, alertou-se ao fato de que a parede móvel rígida da caixa do modelo que induz à deformação pode gerar interpretações falsas. As propriedades mecânicas da parede móvel, de madeira ou acrílico, contrastam desproporcionalmente daquelas do material analógico empregado na modelagem.

Neste estudo, emprega-se o termo anteparo no sentido de Byrne et al. (1993). Os referidos autores desenvolveram estudo teórico sobre a importância mecânica do anteparo (o "backstop") em zonas de subducção. Conceituaram o anteparo, como o domínio estrutural que gera a frente de deformação e que pode exercer influência sobre a cinemática da área em compressão.
Pretende-se, no presente trabalho, apresentar o resultado do estudo do efeito da parede móvel rígida de uma caixa de experimentos sobre estruturas compressivas geradas em areia seca. O objetivo é simular a parede da caixa, o anteparo, normalmente constituído por acrílico ou madeira, com material analógico, e descrever a sua influência sobre a frente de deformação. Para a comparação dos resultados utilizou-se, em um dos modelos, somente a parede de acrílico.

\section{CONDIÇÕES DE CONTORNO DOS EXPERIMENTOS}

Nos experimentos realizados utilizou-se areia seca, de granulometria entre 200 e $300 \mathrm{~m}$, colorida artificialmente, caracterizada por um ângulo de fricção interno de 30 , que eqüivale ao ângulo de atrito interno médio das rochas da crosta superior, de reologia Navier-Coulomb. A escala utilizada foi de 1: 100.000 de maneira que $1 \mathrm{~cm}$ no modelo representa $1 \mathrm{~km}$ no protótipo da natureza.

Em caixas de experimento de $30(40) \times 20 \times 10 \mathrm{~cm}$ (comprimento $\mathrm{x}$ largura $\mathrm{x}$ altura) gerou-se em uma deformação compressiva, um sistema duplex do tipo pilha antiformal em areia, com o anteparo constituído também por areia (ou areia intercalado por finos horizontes de micas). A parede frontal móvel conectada ao motor, de acrílico, foi montada a $20 \mathrm{~cm}$ da frente de deformação, distância suficiente para não interferir no domínio estrutural em estudo (figura 1A).

Montaram-se cinco modelos, quatro com o objetivo de se analisar a ação do anteparo, constituído por material analógico, sobre o sistema compressivo (modelos 1, 2, 3 e 4; figura 1B) e um, a título de comparação, empregando-se a tradicional parede móvel rígida, o anteparo de acrílico, diretamente no material a ser deformado (modelo 5 ; figura $1 \mathrm{~B}$ ).

Os esquemas da figura 1B mostram as condições de contorno de cada modelo. Os experimentos 1 a 4 , com o anteparo formado por material analógico, são 


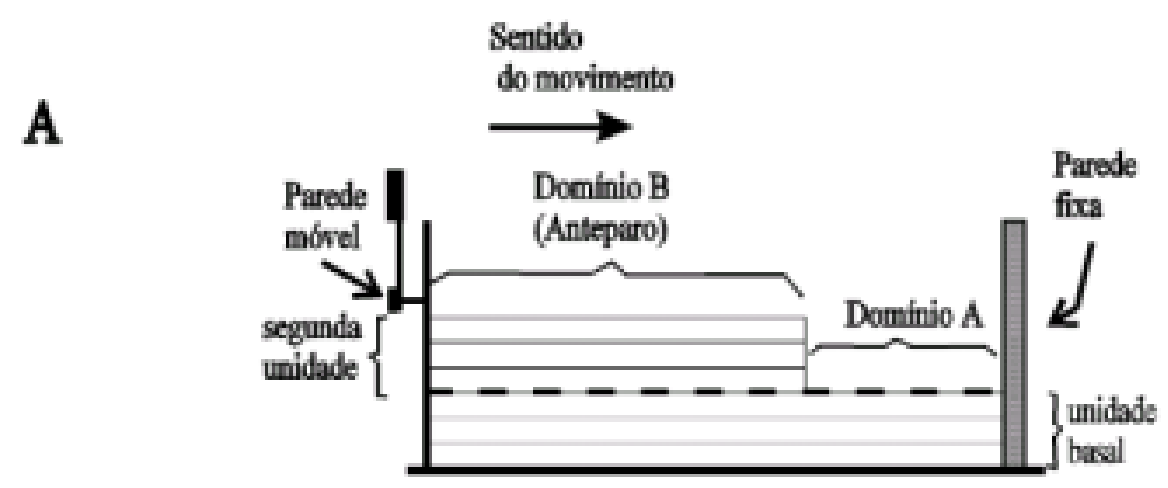

B
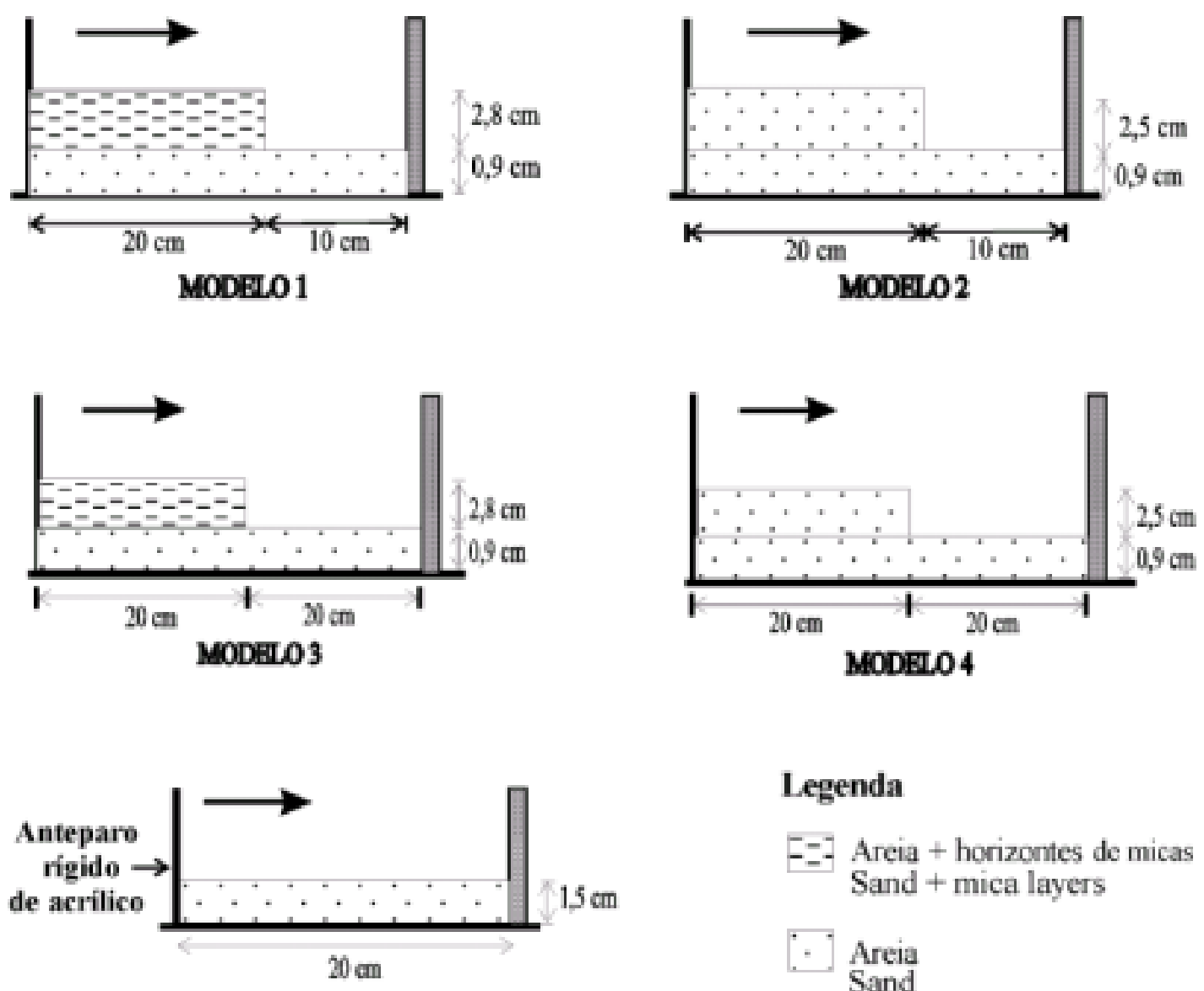

Legenda

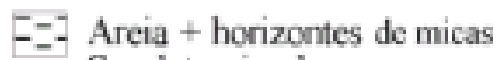

Sand + mica layers

\section{MODELS}

\section{Areia}

Sand

Figura 1: As caixas dos experimentos, em corte. A: Uma caixa de experimento ilustrando os domínios estruturais. B: As caixas dos modelos 1 a 5, com respectivas condições de contorno.

Figure 1: The model boxes in section. A: A model box showing the structural domains. B: The model boxes

1 to 5 with its respective contour conditions.

constituídos por duas unidades: uma unidade basal, ocupando toda a área, da parede fixa à parede móvel da caixa do experimento, e uma segunda unidade, cuja deposição iniciou-se a uma distância de $10 \mathrm{~cm}$ (modelos 1 e 2) e $20 \mathrm{~cm}$ (modelos 3 e 4) da parede fixa. A segunda unidade, sobreposta apenas parcialmente sobre a primeira, assume o papel de anteparo em relação ao sistema de estruturas compressivas, geradas na unidade basal durante a deformação.

Nos modelos 1 a 4, a unidade basal é constituída por 3 camadas de areia de $0,3 \mathrm{~cm}$ de espessura de cores diferentes enquanto a segunda unidade tem composição variada. Nos modelos 1 e 3, é formada por 4 camadas de areia $(0,5 \mathrm{~cm}$ de espessura), intercaladas por horizontes de $0,2 \mathrm{~cm}$ de micas, e nos modelos 2 e 4 , por 5 camadas de areia sem intercalação de micas. Denomina-se domínio 
A, a porção da caixa coberta apenas pela unidade basal, e domínio $\mathrm{B}$, aquela coberta pelas duas unidades.

O modelo 5 é constituído por uma única unidade, composta por três camadas de $0,5 \mathrm{~cm}$ cada.

As pequenas espessuras das camadas de areia nestas modelagens, tem como finalidade gerar maior número de falhas de cavalgamento.

$\mathrm{Na}$ descrição dos experimentos, os valores de encurtamento são fornecidos em porcentagens calculadas pela relação (compressão efetuada / comprimento inicial dos experimentos) x 100 .

Os modelos foram montados sobre uma base de acrílico, caracterizada por baixo coeficiente de atrito (Krantz 1991). Nos modelos 1 e 2, de $30 \mathrm{~cm}$ de comprimento total, provocou-se um encurtamento de $53 \%$ e nos modelos 3 e 4 , de $40 \mathrm{~cm}$ de comprimento inicial, uma compressão de $55 \%$. O modelo 5 , o único experimento efetuado com o anteparo de acrílico, possui $20 \mathrm{~cm}$ de comprimento total e foi submetido a um encurtamento máximo de $70 \%$. Todos os experimentos foram documentados através de sucessivas fotos durante a compressão, em intervalos de $2 \mathrm{~cm}$. Cada modelagem foi repetida várias vezes, para a confirmação dos resultados.

Cortes efetuados nas modelagens ao término dos experimentos, demonstram que o efeito do atrito dos vidros laterais sobre as estruturas, em perfil, é relativamente pequeno. Seções cortadas, a $2 \mathrm{~cm}$ de distância, mostram apenas uma definição mais precisa do traço das falhas de cavalgamento que, ao longo do vidro, comumente assumem aspecto de uma zona de cisalhamento. Em planta, o atrito lateral induz uma curvatura nas falhas de empurrão, convexa em direção ao antepaís.

Repetidas modelagens demonstram que pequenas irregularidades durante a montagem do experimento, às vezes de difícil controle (p. ex. variações na espessura das sucessivas camadas ou na altura total do pacote de areia) podem produzir uma deformação heterogênea na geometria do sistema deformacional.

\section{MECÂNICA DA GERAÇÃO DE CINTURÕES DE ENCURTAMENTO}

O desenvolvimento de sistemas duplex contracionais com propagação por colapso da lapa ("piggy back propagation”), foi simulado por vários autores, em areia seca. Entre outros, Mulugeta \& Koyi (1987) estudaram a cinemática de um sistema imbricado de falhas de empurrão e descreveram a formação progressiva de rampas, em direção ao antepaís, com concomitante verticalização das falhas mais antigas, previamente formadas (figura 2).

Simulações de sistemas de falhas compressivas para o estudo da cinemática de pilhas antiformais, foram efetuadas recentemente (Gomes em prep.) em pacotes de areia com espessura entre 3 e $5 \mathrm{~cm}$. Os experimentos demonstram que pilhas antiformais, no sentido de McClay (1992)(figura 3), somente se formam na presença de um anteparo constituído por material analógico.

Em modelos físicos, o processo deformacional de encurtamento se inicia com o deslizamento da coluna de

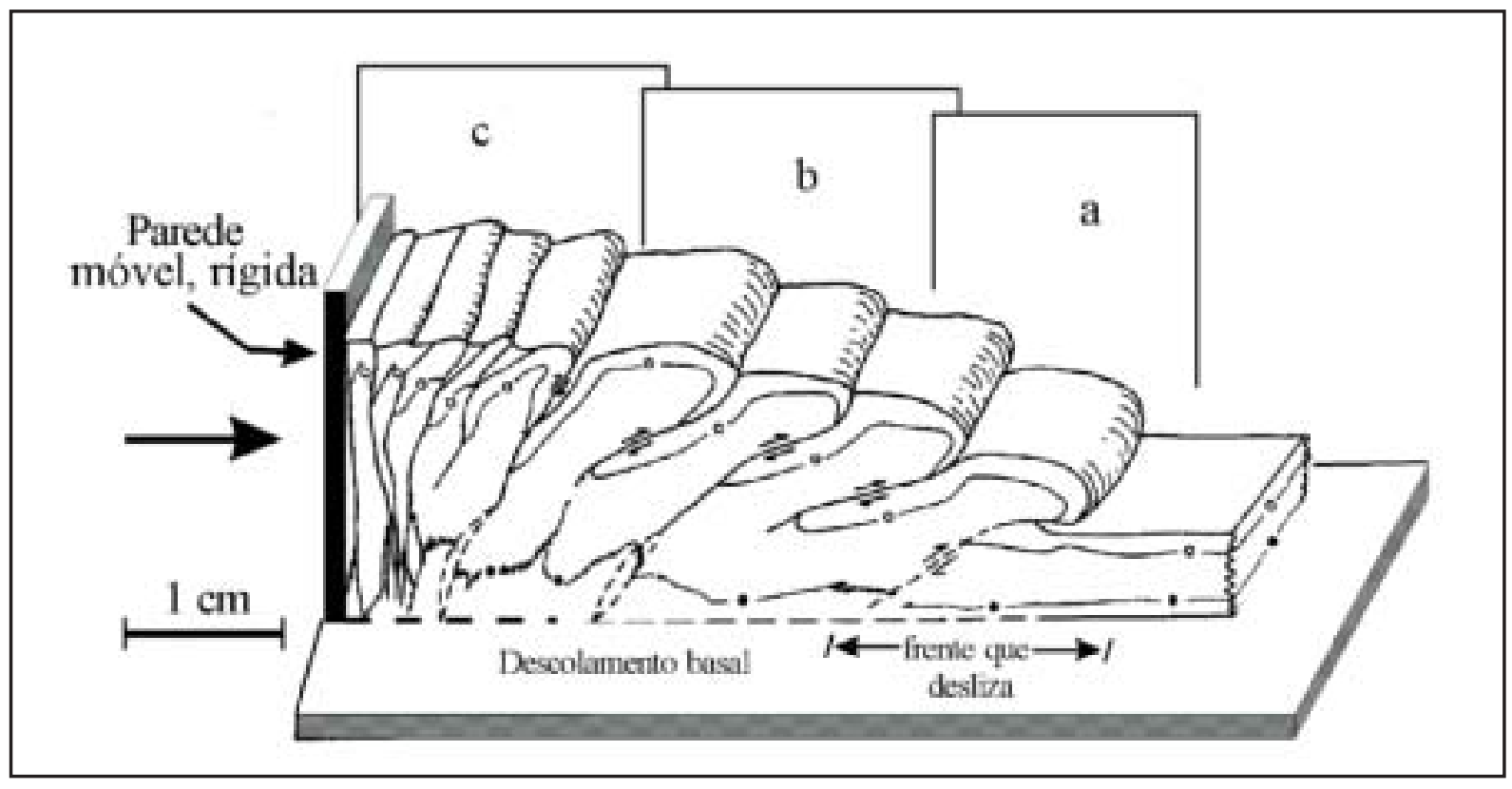

Figura 2: Desenho esquemático de um sistema duplex em um modelo físico, mostrando diferentes regimes deformacionais: a - Antepaís, domínio de propagação dos empurrões; b - Domínio de rotação anti-horária das lascas de empurrão; c - Pós-país, domínio no qual ocorre o aprisionamento das lascas de empurrão entre o anteparo e o domínio b, resultando fluxo de material na vertical (modificado de Mulugeta \& Koyi 1987).

Figure 2: Schematic drawing of a duplex system in a physical model, showing different strains a -foreland; domain of thrust propagation; $\boldsymbol{b}$ - Domain of anticlock- wise rotation of the thrust slabs; $\boldsymbol{c}$ - Hinterland; domain where the thrust slabs are confined between shield and domain b, resulting in vertical flow of material (modified after Mulugeta \& Koyi 1987). 
areia sobre a base da caixa do experimento, que representa o descolamento basal, gerando espessamento no antepaís. $\mathrm{O}$ aparecimento da primeira falha de empurrão ocorre associado a um retrocavalgamento, originando uma pequena quilha (estrutura "pop-up"). A capa da primeira falha é empurrada sobre e ao longo da superfície de cavalgamento recém-formada e os processos de deslizamento da coluna de areia, espessamento e mais novas, pelos processos acima descritos (figuras 4A, B; 5A; 6A e 7A, B).

O comprimento maior do domínio A $(20 \mathrm{~cm})$ nos experimentos 3 e 4 , gera além do pilha antiformal um novo empurrão, isolado, no antepaís (figuras 6B e 7B). Este, no entanto, é rapidamente integrado ao sistema à medida que o encurtamento prossegue, empurrando a pilha antiformal sobre o cavalgamento mais novo.

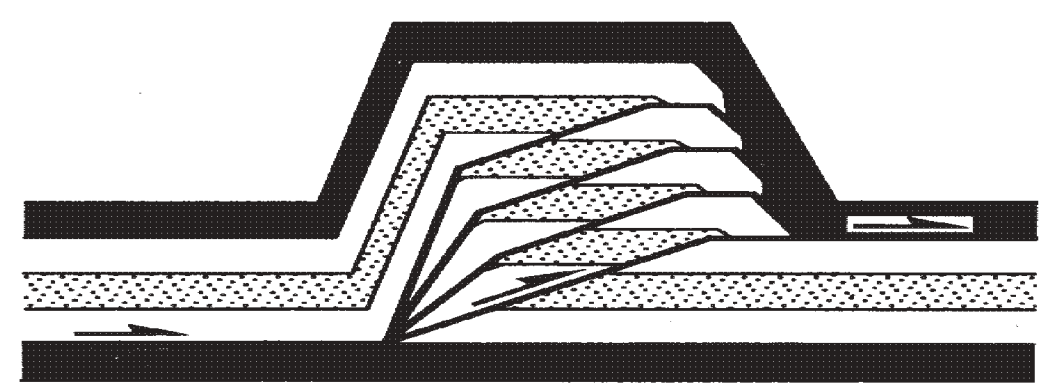

Figura 3: Pilha antiformal, segundo McClay (1982).

Figure 3: Antiformal pile, after McClay (1982).

falhamento, voltam a se repetir. A formação da segunda falha no antepaís, causa rotação antihorária da primeira e induz um processo de ejeção da quilha, comprimida entre $\mathrm{o}$ anteparo e o bloco da capa da falha mais nova. $\mathrm{O}$ efeito progressivo da deformação gera um número crescente de empurrões no antepaís até que a parede fixa, posicionada na extremidade oposta da caixa do experimento, ofereça resistência à continuidade do processo. Acentua-se, então, a deformação atrás, no póspaís, no qual as falhas se aproximam entre si provocando intensa rotação anti-horária e forte ejeção de material na vertical (figura 2).

A espessura extremamente baixa da coluna de areia $(0,9 \mathrm{~cm})$ somado ao baixo coeficiente de atrito basal geraram, em presentes modelos, uma seqüência de processos algo diferente. Ao invés do sistema duplex sintético forma-se uma pilha antiformal, por deformação simultânea em antepaís e pós-país. No início da deformação, ocorre, como acima descrito, deslizamento da coluna de areia, espessamento e falhamento. No entanto, o espessamento que precede o segundo empurrão gera forte deformação para trás, no domínio da primeira falha que sofre rotação anti-horária e fluxo de material na vertical. Este fato se repete antes da formação de cada nova falha, durante todo o processo de encurtamento, dando origem à pilha antiformal (figuras $4 \mathrm{~A}$ e $\mathrm{B}$; 7A e B).

\section{DESCRIÇÃO DOS EXPERIMENTOS}

Nos modelos 1 a 4, o início do falhamento ocorre após encurtamento da ordem de 5,0 e 6,6\%. Até taxas de encurtamento de $26 \%$ (modelo 1 e 2 ) e $20 \%$ (modelos 3 e 4) observa-se comportamento homogêneo no desenvolvimento da pilha antiformal (figuras 4A, 5A, $6 \mathrm{~A}$ e 7A). O referido sistema de estruturas é gerado pelo cavalgamento das lascas mais antigas (de trás) sobre as
Processo semelhante é observado no modelo 5 (figuras $8 \mathrm{~B}$ e C). Neste caso, no entanto, a rigidez do anteparo inibe o cavalgamento de uma lasca sobre a outra causando forte verticalização das falhas e intenso fluxo de material na vertical.

Com a continuidade da deformação, o sistema compressivo formado oferece crescente resistência ao encurtamento. Nos modelos 1 a 4, a pilha antiformal gera deformação para trás, no seu pós-país, o anteparo de areia (figuras 4B, 5B, 6B e 7B).

$\mathrm{O}$ anteparo constituído por areia com intercalações de mica (modelos 1 e 3), possui propriedades plásticas quando comparado com aquele composto por areia pura (modelos 2 e 4). Nos experimentos 1 e 3, após 25 e 33\% encurtamento respectivamente, o anteparo sofre progressiva flexão (figuras 4B, C, D e 6B, C, D) enquanto nos modelos 2 e 4, a deformação é acomodada por um retrocavalgamento (figuras $5 \mathrm{~B}, \mathrm{C}, \mathrm{D}$ e $7 \mathrm{~B}, \mathrm{C}, \mathrm{D}$ ).

Nos modelos 1 e 2 (domínio $A=10 \mathrm{~cm}$ ), além da deformação no anteparo ocorre outra, "tardia”, após 47\% de encurtamento, afetando a própria pilha antiformal. No experimento 1, esta deformação se manifesta por deslizamento interestratal no domínio do anteparo (domínio B), que gera uma deformação na porção superior da pilha antiformal (figuras 4C e D). No experimento 2, um empurrão é desenvolvido naquele domínio, deformando o sistema compressivo, também na sua parte mais alta (figuras 5C e D). Uma deformação "tardia" do domínio A, é mínima no modelo 3 e ausente no modelo 4 , devido à distância maior até a parede fixa da caixa do experimento e portanto à menor resistência oferecida ao encurtamento.

No modelo 5, no qual a deformação se desenrola diretamente frente à parede de acrílico, rígida, as feições características do encurtamento são: rotação anti-horária dos empurrões e fluxo de material na vertical (figuras 8C e D). 
$1.0 \mathrm{~cm}$

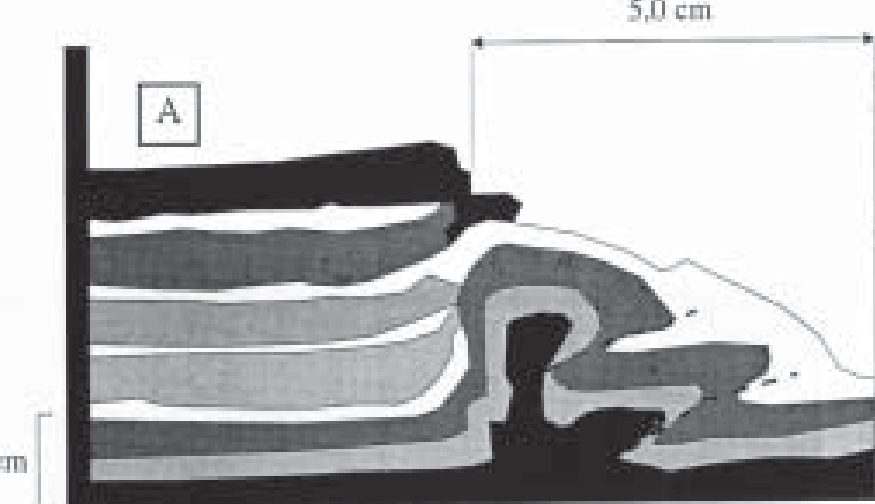

$1,0 \mathrm{~cm}$

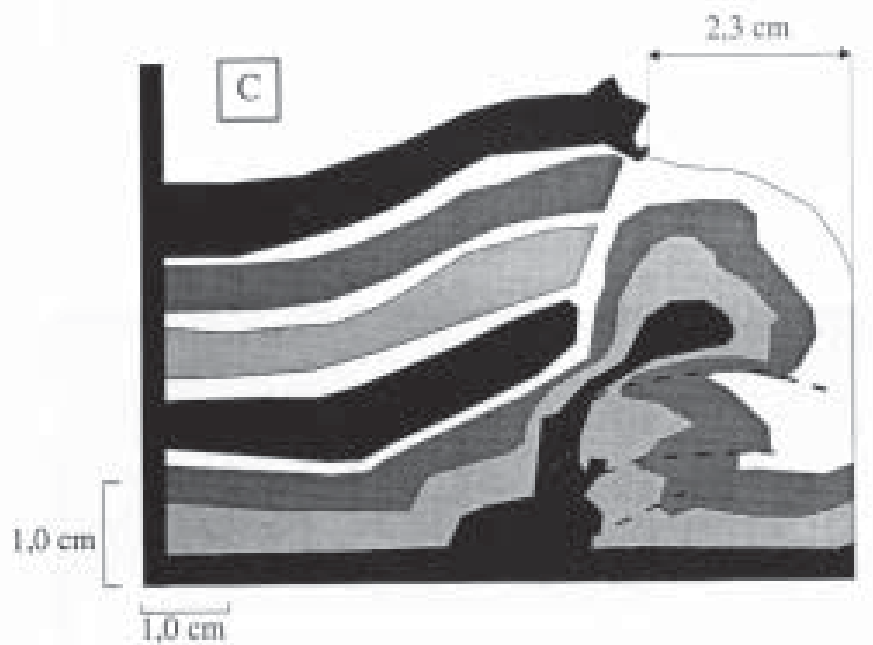

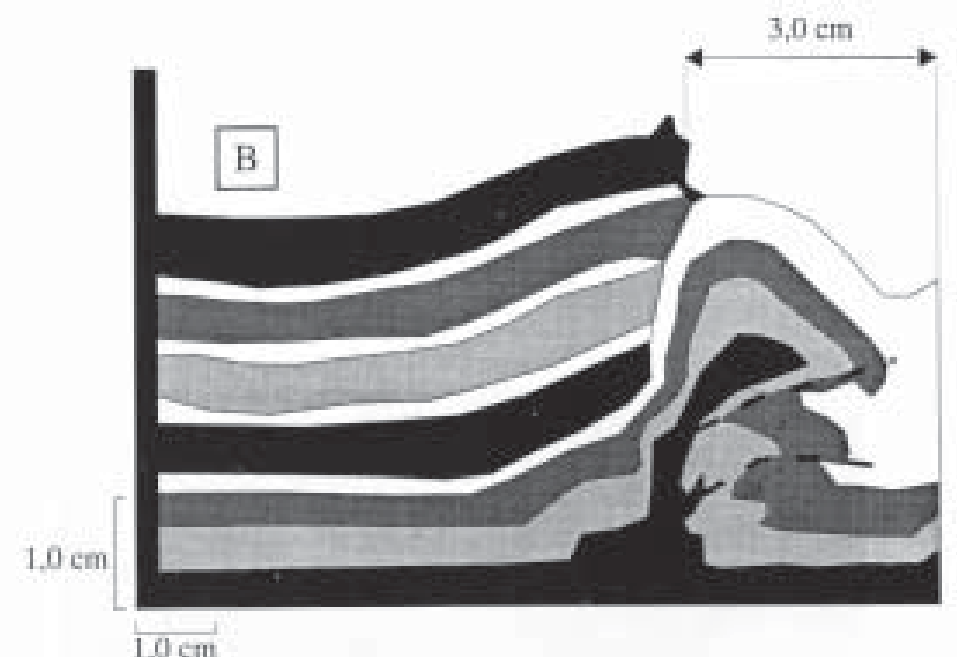

$1.0 \mathrm{~cm}$

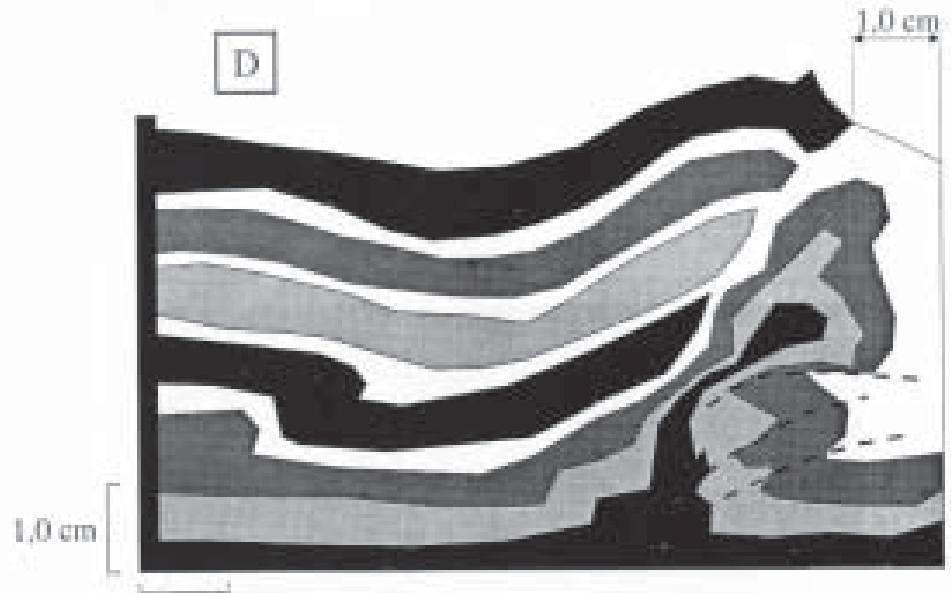

$1,0 \mathrm{~cm}$

Figura 4: Fases progressivas de encurtamento do Modelo 1. A) 27\%; B) 33\%; C) 47\% e E) $53 \%$.

Figure 4: Progressive phases of shortening of Model 1. A) 27\%; B) 33\%; C) 47\% e E) 53\%. 

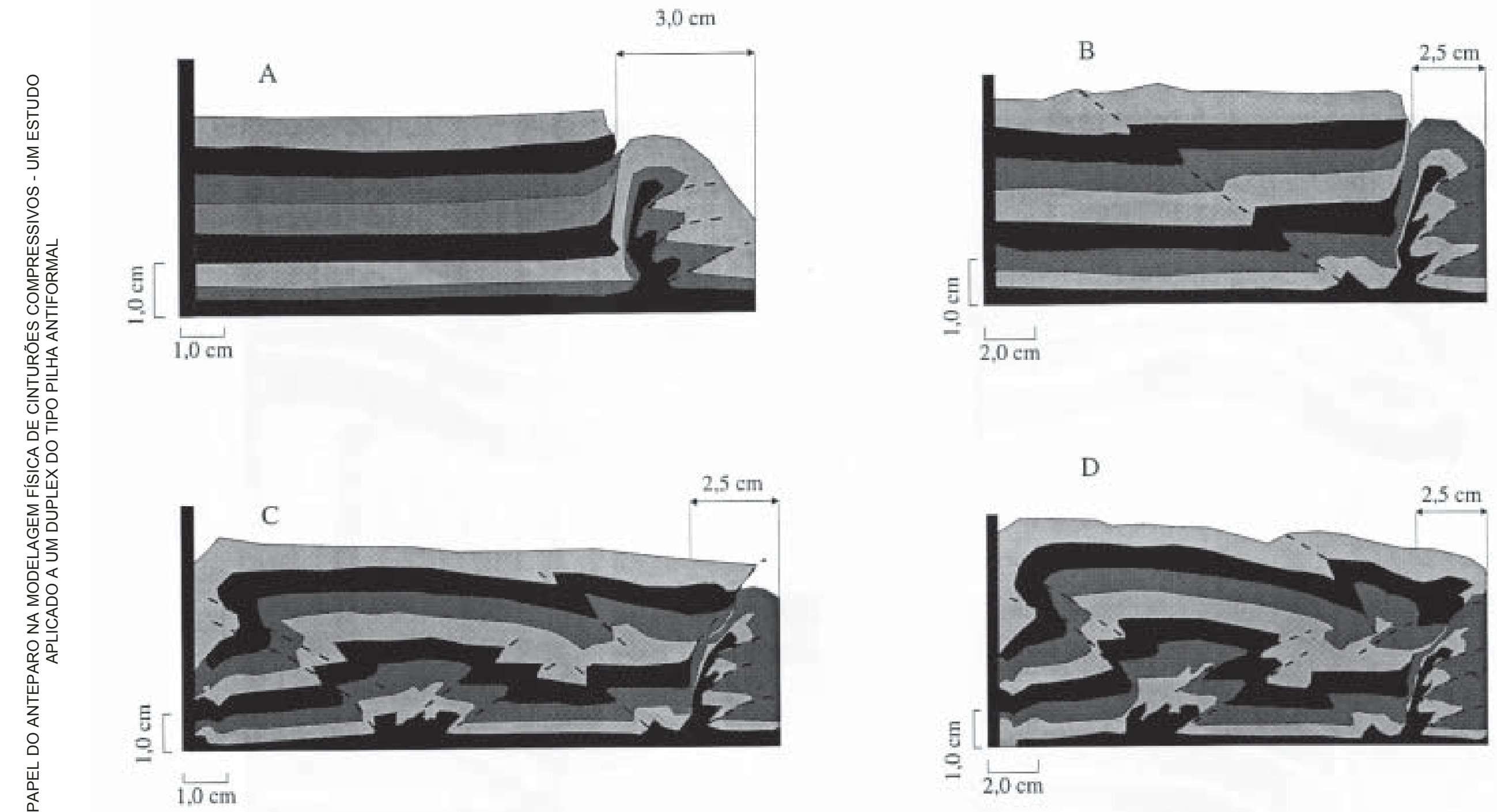

Figura 5: Fases progressivas de encurtamento do Modelo 2. A) 27\%; B) 33\%; C) 47\% e E) $53 \%$.

Figure 5: Progressive phases of shortening of Model 2. A) 27\%; B) 33\%; C) $47 \%$ e E) $53 \%$. 

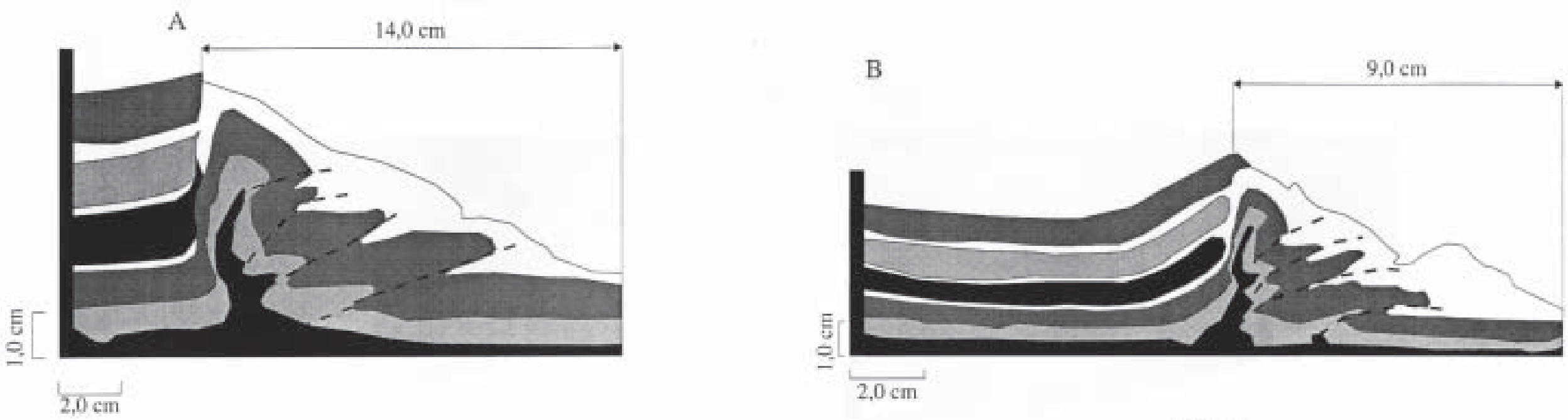

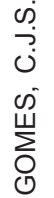
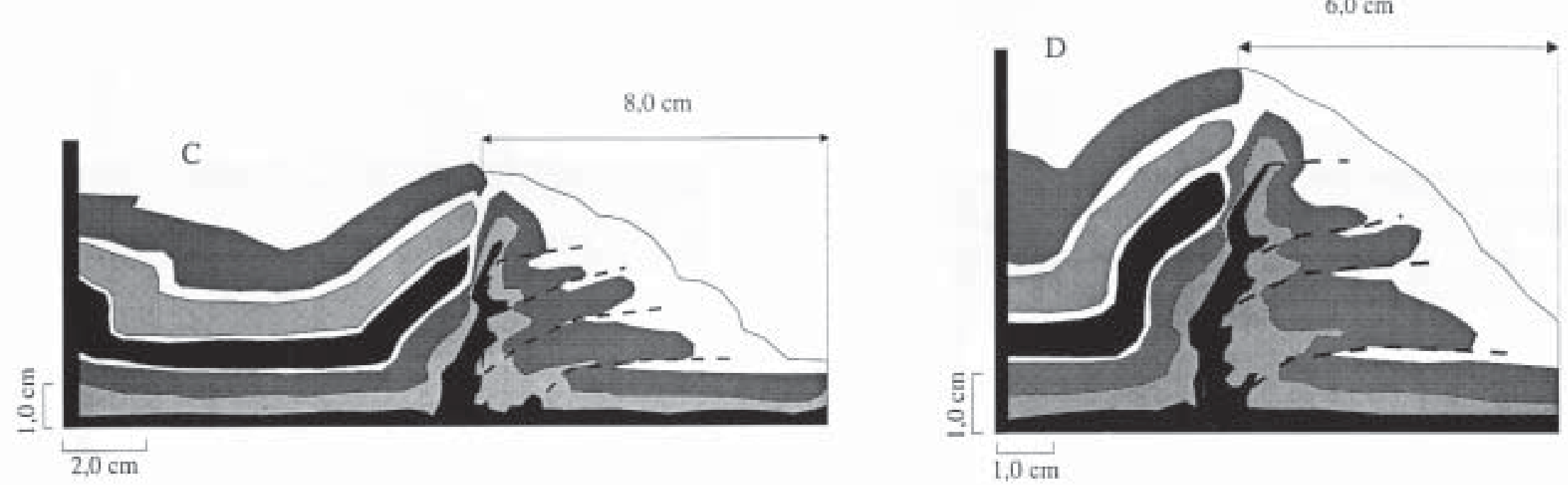

Figura 6: Fases progressivas de encurtamento do Modelo 3. A) 20\%; B) 35\%; C) $40 \%$ e E) $55 \%$.

Figure 6: Progressive phases of shortening of Model 3. A) 20\%; B) $35 \%$; C) $40 \%$ e E) $55 \%$. 

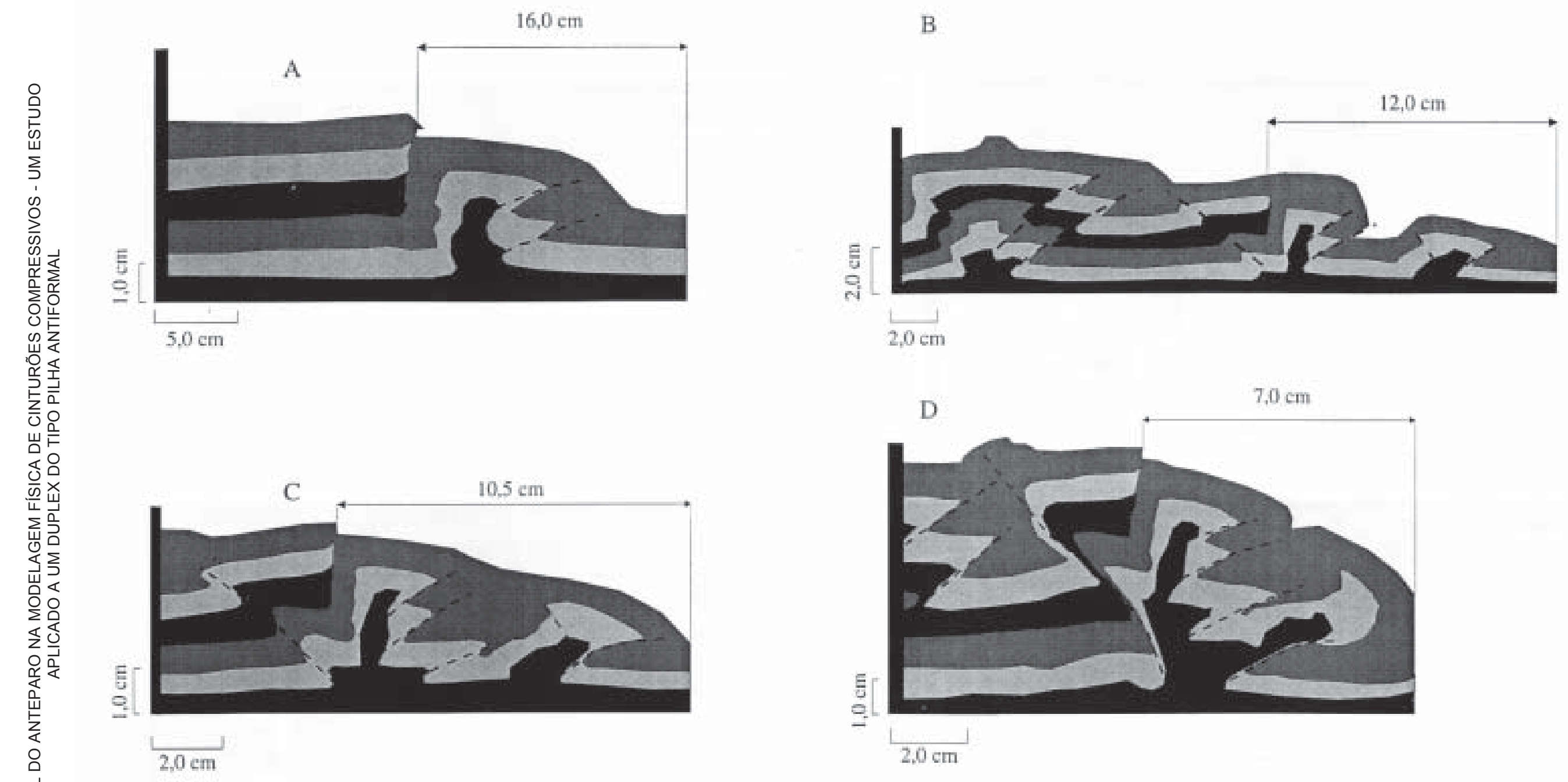

Figura 7: Fases progressivas de encurtamento do Modelo 4. A) 20\%; B) 35\%; C) $40 \%$ e E) $55 \%$.

Figure 7: Progressive phases of shortening of Model 4. A) 20\%; B) 35\%; C) $40 \%$ e E) $55 \%$. 

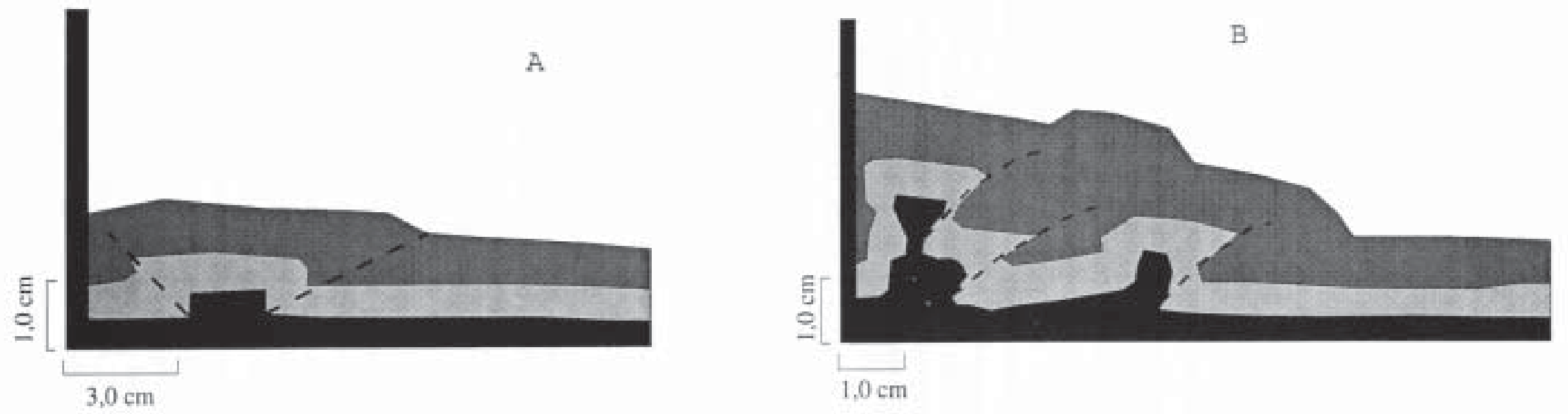

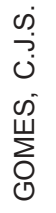
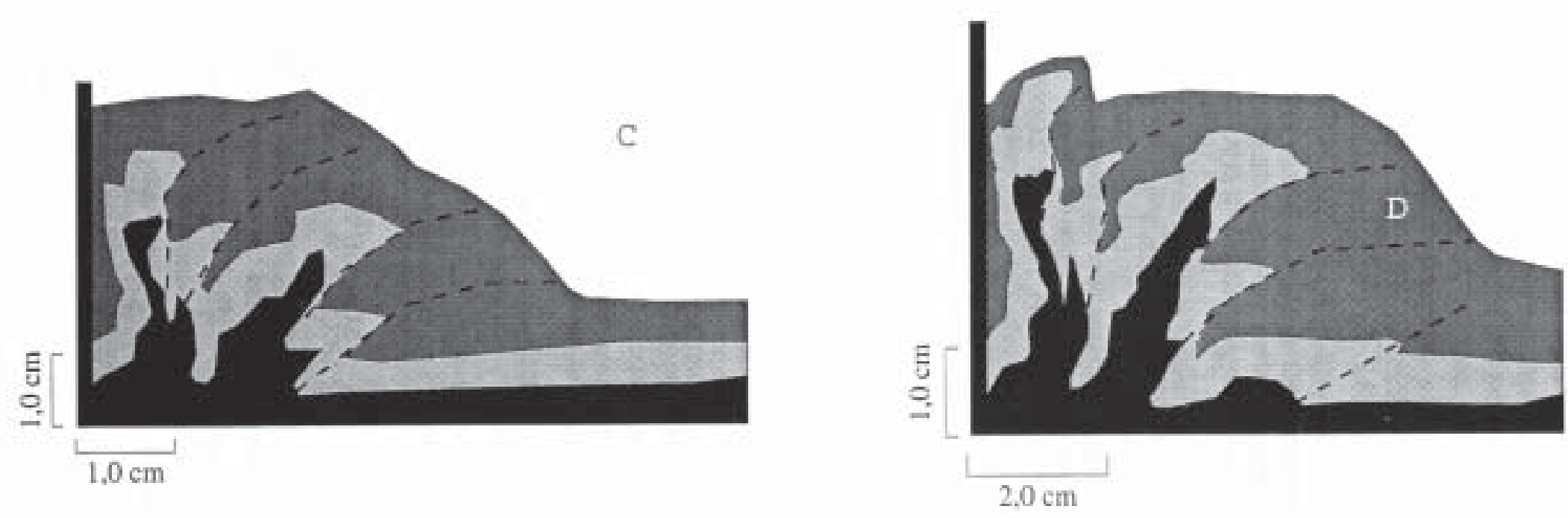

Figura 8: Fases progressivas de encurtamento do Modelo 5. A) 20\%; B) 40\%; C) $50 \%$ e E) $70 \%$.

Figure 8: Progressive phases of shortening of Model 5. A) $20 \%$; B) $40 \%$; C) $50 \%$ e E) $70 \%$. 


\section{DISCUSSÃO E CONCLUSÕES}

Os modelos estudados, que simulam a compressão em ambiente de deformação epidérmica, mostram a geração de cinturões contracionais, em pacotes de areia de baixa espessura. Um obstáculo no antepaís (a parede fixa da caixa do experimento) gera forte resistência à continuidade do processo deformacional produzindo diferenças geométricas nos vários experimentos.

O modelo 5, no qual se utilizou um anteparo de acrílico para gerar o encurtamento, representa o procedimento adotado mundialmente em caixas de experimentos. Neste caso, o processo deformacional é caracterizado pela verticalização das falhas mais antigas. Embora empurrões verticais ainda não tenham sido descritos na natureza não se descarta a possibilidade de existirem, gerados através de processo similar. Sugere-se, no entanto, que a rotação anti-horária exagerada das falhas represente o efeito do anteparo, de material não analógico, sobre estruturas desenvolvidas em areia.

Nos modelos 1 a 4, também ocorre rotação antihorária das falhas a medida que estas se formam, no entanto o anteparo constituído por material analógico acomoda uma parte da deformação. Desta maneira a ejeção do teto dos empurrões, o fluxo de material na vertical, ocorre de maneira menos intensa. A crescente resistência oferecida pelo antepaís resulta na deformação do próprio anteparo, por flexão ou retrocavalgamento.

Nos experimentos observou-se que, sob baixa magnitude de deformação, o material analógico utilizado para simular o anteparo (modelos 1 a 4), não influi na geometria da pilha antiformal. No entanto, com o aumento gradativo da compressão, aumenta progressivamente a resistência oferecida pela própria pilha antiformal à deformação, modificando o campo local de esforços. Neste momento, as diferentes condições de contorno dos modelos, anteparo constituída por material analógico rúptil (areia pura) ou plástico (areia com intercalações de mica), alteram o inventário estrutural.
A comparação entre os modelos 1 a 4 e 5 revela além das diferenças geométricas que, sob mesma magnitude de encurtamento, o modelo com anteparo rígido causa uma deformação mais intensa.

O presente estudo demonstra que em experimentos de modelagem física analógica não se deve desprezar a ação do anteparo sobre sistemas compressivos. Dependendo das propriedades mecânicas deste, este gera sistemas de estruturas diferentes: duplex com falhas verticais ou pilhas antiformais.

\section{AGRADECIMENTOS}

A autora agradece à UFOP e ao CNPq pelo suporte financeiro concedido através de bolsas de Iniciação Científica (programa PIC e bolsa por quota, processo no. 523045/95-6), aos bolsistas Juliano E. Ferreira e Gesner J. I. Santos pelo apoio nos trabalhos de laboratório, ao colega André Danderfer Filho pela leitura crítica do manuscrito e a Zulmeire C. Cota e Beatriz M. Baêta pela competência na execução dos desenhos.

\section{BIBLIOGRAFIA}

BYRNE, D. S.; WANG, W. \& DAVIS, D. M. 1993. Mechanical role of backstops in the growth of forearcs. Tectonics, 12 (1), p. 123-144.

GOMES, C. J. S. (em prep.). Geometry and kinematics of experimental antiformal stacks.

HANCOCK, P. L. 1994. Continental Deformation. Pergamon Press; $421 \mathrm{pp}$.

KRANTZ, R. W. 1991. Measurements of friction coefficients and cohesion for faulting and fault reactivation in laboratory models using sand and sand mixtures. Tectonophysics, 188, p. 203207.

MARSHAK, S. \& WILKERSON, M. S. 1992. Effect of overburden thickness on thrust belt geometry and development. Tectonics, 11 (3), p. 560-566.

McCLAY, K. R. 1992. Glossary of thrust tectonics terms. In: McClay (Ed.) Thrust Tectonics. Chapman \& Hall, London, p. 419-433.

MULUGETA, G. \& KOYI, H. 1987. Three-dimensional geometry and kinematics of experimental piggyback thrusting. Geology, 15 , p. $1052-1056$.

PRICE, N. J. \& COSGROVE, J. W. 1990. Analysis of geological structures. Cambridge University Press. 502pp. 